\title{
Challenges of Providing Confidential Care to Adolescents in Urban Primary Care: Clinician Perspectives
}

\author{
M. Diane McKee, $M D, M S^{1}$ \\ Susan E. Rubin, MD, MPH \\ Giselle Campos, $B A^{1}$ \\ Lucia F. O'Sullivan, $P b D^{2}$
}

'Department of Family and Social Medicine Montefiore Medical Center/Albert Einstein College of Medicine, Bronx, New York

${ }^{2}$ Department of Psychology, University of New Brunswick, Fredericton, New Brunswick, Canada

Conflicts of interest: authors report none.

\section{CORRESPONDING AUTHOR}

M. Diane McKee, MD, MS

Department of Family and Social Medicine Albert Einstein College of Medicine 1300 Morris Park Ave

Mazer 417

Bronx, NY 10461

Diane.Mckee@einstein.yu.edu

\begin{abstract}
PURPOSE Clinician time alone with an adolescent has a major impact on disclosure of risk behavior. This study sought to describe primary care clinicians' patterns of delivering time alone, decision making about introducing time alone to adolescents and their parents, and experiences delivering confidential services.

METHODS We undertook qualitative interviews with 18 primary care clinicians in urban health centers staffed by specialists in pediatrics, family medicine, and adolescent medicine.

RESULTS The annual preventive care visit is the primary context for provision of time alone with adolescents; clinicians consider the parent-child dynamic and the nature of the chief complaint for including time alone during visits for other than preventive care. Time constraints are a major barrier to offering time alone more frequently. Clinicians perceive that parental discomfort with time alone is rare. Many clinicians wrestle with internal conflict about providing confidential services to adolescents with serious health threats and regard their role as facilitating adolescent-parent communication. Health systems factors can interfere with delivery of confidential services, such as inconsistent procedures for determining whether unaccompanied youth would be seen.
\end{abstract}

CONCLUSION Despite competing time demands, clinicians report commitment to offering time alone during preventive care visits and infrequently offer it at other times. Experienced clinicians can gain skills in the art of managing complex relationships between adolescents and their parents. Office systems should be developed that enhance the consistency of delivery of confidential services.

Ann Fam Med 2011;9:37-43. doi.10.1370/afm.1186.

\section{INTRODUCTION}

Adolescents' concerns about privacy can prevent them from seeking health care ${ }^{1-3}$ especially for specific sensitive health services. ${ }^{4}$ Those with privacy concerns are less likely to talk openly with a health care clinician about important health issues, such as substance use, mental health, and risky sex., Recognizing that confidentiality is critical to high-quality care for adolescents, professional health care organizations have adopted policy statements and practice guidelines that support the provision of confidential services. ${ }^{6,7}$

To provide confidential services to adolescents, primary care clinicians must provide time alone for private consultation during visits when youth attend with their parents or guardians. Clinicians must also provide services to youth who attend visits without parents (with or without parental knowledge, hereafter referred to as unaccompanied youth). Finally, clinicians must offer confidential follow-up of concerns identified during visits. Many youth do not have time alone with clinicians during visits ${ }^{8}$; there is substantial variation, with younger adolescents, females, and Hispanics least likely to experience time alone. ${ }^{9}$ These findings have prompted calls for research 
on barriers to providing such care. ${ }^{10}$ In particular, little research has included clinicians' perspectives. ${ }^{11}$

This study explored clinicians' perspectives on delivering confidential services (seeing unaccompanied youth confidentially, offering time alone, and providing confidential follow-up in routine primary care) as a formative step in the design of an intervention to improve delivery of care to adolescents in urban primary care settings. Unlike studies that have relied entirely on clinicians' retrospective reports or reports from adolescents, we conducted a mixed method study involving clinician card completion followed by in-depth interviews to explore clinicians' experiences with the provision of confidential services for youth, the contextual features associated with delivery of confidential care, and the barriers or obstacles to extending such care.

\section{METHODS}

We conducted a quantitative card study in which clinicians recorded data on a pocket card after visits with adolescents. This method served to (1) document elements of care provided, including time alone and specific services provided; and (2) ground the qualitative interview in recent actual encounters. In this article, the results of the in-depth interview component are reported. The current study was approved by the institutional review boards of Montefiore Medical Center and Albert Einstien College of Medicine, Bronx, New York.

\section{Participants}

We invited primary care clinicians from 7 practices $(3$ family medicine, 3 medicine-pediatrics, and 1 adolescent specialty practice) to participate. Practices were members of an urban, practice-based research network, chosen to reflect diversity of size, staffing, and practice demographics for the planned intervention phase that this study preceded. These practices provide comprehensive primary care to low-income, mostly ethnic minority families in the Bronx, New York. At sites with more than 3 eligible clinicians, a list of names was randomly ordered and invitations extended until at least 2 agreed to participate. Clinicians were first invited by e-mail and then contacted by telephone by one of the investigators. After providing consent, clinicians were instructed on how to participate in the card study.

\section{Data Collection Procedure}

\section{Card Completion}

Clinicians completed a pocket card after each of 10 consecutive visits with youth aged 12 to 18 years, regardless of reason for the visit. These cards contained no identifiable information; thus, neither youth nor par- ents provided consent. Each card assessed chief complaint, services provided, whether the adolescent was accompanied by a parent or guardian, and how much of the visit, if any, was spent alone with the adolescent.

\section{Qualitative Interview}

All interviews were conducted by telephone by the second author (S.E.R.), a family physician, and lasted 20 to 45 minutes. The interview guide assessed decision making about when to include time alone, how time alone and confidentiality were introduced, and details regarding difficult interactions with adolescents and/or parents. The interviewer used the cards to ground the clinicians' responses in the qualitative interview to specific interactions. For example, clinicians were asked to reflect on why time alone was offered in one visit but not another. Prompts were used to explore memorable interactions and what factors made them challenging. Interviews were digitally recorded and professionally transcribed.

\section{Analysis}

The research team (2 family physicians, the research coordinator, and a research psychologist) independently read each interview transcript and identified themes. The team met to review each transcript excerpt by excerpt, and to modify and refine a coding template based on this review. Two team members independently reread the transcripts, and subsequently met to apply the codes systematically to all interview data. NVivo software (QSR International Pty Ltd. Version 8,2008$)$ was used to facilitate retrieval and analysis of coded data.

\section{RESULTS}

Of the 20 clinicians who agreed to participate in the card study, 18 completed the subsequent telephone interview. Most clinicians were women (78\%), and they were evenly divided by specialty between family medicine $(50 \%)$ and pediatrics and adolescent medicine (50\%). Nearly one-half were white (44\%), with the rest reporting black, Asian or Pacific Islander, and Hispanic ethnicities. Table 1 displays the demographics of participating clinicians.

\section{Characteristics of Visits Sampled in the Card Study}

Quantitative results from the card component of this study are reported elsewhere. ${ }^{12}$ Briefly, clinicians returned an average of 10.8 cards (range 8 -12) documenting a total of 215 adolescent patient visits (Table 2). Adolescents were unaccompanied for 71 visits (33\%). Of the remaining 144 visits in which a 


\begin{tabular}{|c|c|c|}
\hline Variables & No. & $\%$ \\
\hline \multicolumn{3}{|l|}{ Sex } \\
\hline Female & 14 & 78 \\
\hline Male & 4 & 22 \\
\hline \multicolumn{3}{|l|}{ Type } \\
\hline Family medicine & 9 & 50 \\
\hline Pediatrics & 5 & 28 \\
\hline Adolescent medicine & 4 & 22 \\
\hline \multicolumn{3}{|l|}{ Race/ethnicity } \\
\hline African American, black, or Caribbean & 5 & 28 \\
\hline Asian or Pacific Islander & 3 & 17 \\
\hline Hispanic/Latino & 2 & 11 \\
\hline White & 8 & 44 \\
\hline
\end{tabular}

Table 2. Visit Characteristics ( $N=215)$

\begin{tabular}{|c|c|c|}
\hline Variables & No. & $\%$ \\
\hline \multicolumn{3}{|l|}{ Type of visit } \\
\hline Annual preventive care visit ${ }^{a}$ & 88 & 43.3 \\
\hline Follow-up ${ }^{b}$ & 55 & 27.1 \\
\hline Same-dayc & 36 & 17.7 \\
\hline Walk-in & 24 & 11.8 \\
\hline Not classified by physician & 12 & 5.6 \\
\hline \multicolumn{3}{|l|}{ Adolescent's reasons for visit } \\
\hline Acute visit & 58 & 27.0 \\
\hline Preventative care examination & 71 & 33.0 \\
\hline Reproductive health mentioned at all & 43 & 20.0 \\
\hline Routine care or chronic disease management & 35 & 16.3 \\
\hline Other & 8 & 3.7 \\
\hline Parent/guardian attended visit with adolescent & 144 & 67.0 \\
\hline Confidentiality explained to adolescent during visit ${ }^{d}$ & 120 & 83.3 \\
\hline Confidentiality explained to parent during visit ${ }^{d}$ & 60 & 41.7 \\
\hline Parent asked to leave room ${ }^{\mathrm{d}, \mathrm{e}}$ & 93 & 64.6 \\
\hline $\begin{array}{l}\text { Identified needs requiring confidential care } \\
\text { follow-up }\end{array}$ & 85 & 39.6 \\
\hline \multicolumn{3}{|c|}{$\begin{array}{l}\text { a Annual visit for preventive care services (check-up or physical examination). } \\
\text { b Scheduled visit for follow-up of previously identified condition. } \\
\text { 'Appointment obtained by calling for same-day access. } \\
\text { d In } 144 \text { cases a parent/guardian attended the visit with adolescent. } \\
\text { e Physician indicated parent left room without being asked in an additional } \\
3 \text { cases. }\end{array}$} \\
\hline
\end{tabular}

parent attended the visit, 46 (31.9\%) involved no time alone with the adolescent. Clinicians had seen most adolescents (73\%) previously.

\section{Decisions Regarding Time Alone in Visits}

Clinicians emphasized that they always included time alone during annual check-ups, typically starting at age 12 or 13 years. Many clinicians indicated that although age was the most important factor, they also considered the adolescent's physical development:

I usually look at the physical maturity of the child. If it's a 12 -year-old that looks like a 14 -year-old, I'll probably ask the mom to leave. If it's a 12-year-old that looks like an 8-yearold, I probably won't (Family physician).

Several clinicians described a process to assess emotional maturity as well, opting to ask questions with the parent in the room for youth considered developmentally younger.

For nonpreventive care visits, clinicians decided to provide time alone based on the chief complaint (usually when a sexual health-related problem was suspected and sensitive questions were required).

Clinicians also assessed the dynamic between parent and teen, and looked for cues that there may be more to the presentation than was being revealed:

If they come in with things that are kind of vague... or it's just you get a feeling this doesn't seem to be the whole picture, then I'll do [time alone].... Or some kind of psychological stress, something that they're not talking about... (Family physician).

The dynamic between the parent and the child, the dynamic between them and me... just sort of weigh the situation.... Does somebody look angry to be there? ... I try to respond to whatever they bring in (Adolescent medicine clinician).

Cited by almost all clinicians, time constraints were the main barrier to offering time alone more consistently. Clinicians acknowledged that including time alone more frequently would be ideal, but they experienced relief that some acute visits could remain brief, noting that "some days are so crazy that you just hope for that ear infection."

\section{Introducing Time Alone to Parents and Adolescents}

Clinicians indicated that they used scripts of varying complexity to request time alone with adolescents, although usually these scripts were brief. Two key elements were identified: normative statements ("we do this for all teens") and purpose ("to help take better care of your teen" or "to encourage good communication"). Some also tried to define the visit structure for parents, indicating that parents would be asked to leave, but that the visit would conclude with the parent back in the room. Scripts were adjusted when deemed necessary:

And with some, based on the interaction between the patient and the parent... if I have a more overbearing parent, I will be more explicit with what confidentiality boundaries exist (Adolescent medicine clinician).

Clinicians in family medicine and adolescent medicine or pediatrics settings were less likely to report that they routinely described confidentiality in detail to parents, avoiding areas that they considered unnecessarily "confrontational." Several clinicians in these 
settings indicated that preparing the stage in preteen visits helped ease the process:

Sometimes I don't have to even prompt [parents to leave]. They say, "I know, I know I need to leave." Just because it's this ongoing thing where I bring that up enough in the past, and they transition to the preadolescent age that I don't have to keep repeating that (Family physician).

In contrast, when entering care at the adolescent practice, both adolescent and parent are introduced to a practice culture that explains confidentiality at the initial visit and includes time alone at every visit. Clinicians from the adolescent practice described a very standardized approach:

Normally I say, "It's our routine here in our adolescent health center to ask any parent or guardian who accompanies the patient to step out so that we can have some private time with the patient to just go over some additional things that maybe would be more comfortable discussing with us privately." After their first time, they know that that's standard... We just say, "that's how it works here" (Adolescent medicine clinician).

Clinicians described parents as generally accepting of time alone; many stated that most of the time parents seemed "to have one foot out [of] the door" when asked to step out. They were sensitive to parents' initial discomfort or reluctance, but perceived that parents' reaction eased over time as they became accustomed to the idea that doctors "always do that for teenagers."

Moreover, clinicians believed that parents' comfort increases as the adolescent gets older:

The parents generally are okay with it. But sometimes it's dependent on the age.... I think, actually, one of my cards, there was an 11- or 12-year-old...it was the first time that the patient was there and it was pretty difficult to do, to explain why this is the way it is (Adolescent medicine clinician).

Unlike typical interactions with parents, clinicians described their scripts for adolescents as nearly always including a discussion of the privacy of information (eg, "I won't discuss this information with your parents unless you want me to.") and sometimes of the limits of privacy (eg, "I have to share the information if you are going to hurt yourself or someone else.").

\section{Visit Dynamics}

\section{Difficult Situations}

Though only 1 clinician reported a difficult parent interaction during the study period, the remaining clinicians (17 of 18) described previous interactions with resistant or upset parents. These challenging cases sometimes related to asking for time alone with the adolescent:
A mom got really upset when I asked her to leave the room, and I had to explain to mom exactly why we do that, and she was still...kind of persistent 'cause she felt that...she's under my roof. She said, "I should be there for everything." She was not happy about it (Adolescent medicine clinician).

More frequently, challenging interactions with parents arose when parents brought a teenager because of a specific concern (eg, pregnancy or confirmation of "virginity status") and from a parent's desire to know test results:

And then [the mother is] just like, "I don't understand that... I'm the one who brings her in.... I'm the one that's going to be responsible if she gets pregnant. You know, this isn't right. I can't understand why this is the law" (Adolescent medicine clinician).

\section{Managing the Triad}

Clinicians clearly valued their relationships with both parent and adolescent. This triadic relationship, however, could result in significant tension. The choice between protecting adolescent privacy and informing parents was occasionally distressing. Several clinicians acknowledged their own reactions as parents themselves:

You know, I have a 14-year-old daughter myself, so I have to be aware of my own feelings...just acknowledge that and keep working. If my daughter were in the same situation, I would, on the one hand, want her to feel comfortable talking with a health care provider, but on the other hand, I want to know what's going on with my kid (Family physician).

Many recognized that adolescents had limited skills to handle health threats without parental support, especially younger adolescents. The more serious the health concern, the more clinicians experienced conflict, as in this example of concern about pregnancy:

[The mother] said, "I have 2 other little kids, and I'm not willing to take care of somebody else. She's 14 years old.... Who's going to end up taking care of this kid? It's me. So, I know [the adolescent] has the decision, I know it is confidential, but I'm in the middle" (Family physician).

The tension between competing roles was often handled by encouraging parent-teen communication. This clinician described such a discussion with one teenaged patient:

I think your mother knows what's going on. I think she would be helpful in this situation. Maybe you should talk to her about it. I'm not going to talk to her, but I think you should (Pediatrician).

Others described offering to serve as a mediator for enhanced communication: 
I pulled the daughter in, and I said, "Listen, your mom knows what's going on. I don't think you're hiding anything from her. The question for you is, do you want to go home and tell her, or use me as a mediator to sort of decide what it is you're going to do?" And in that case actually she used me... I mean [the teen] was crying, the mom was very upset. But I was able to mediate and facilitate everything that took place in the office (Pediatrician).

\section{Health System Factors}

Clinicians cited several systemic factors that interfere with effective delivery of confidential care. Most noted either lack of protocols or inadequate knowledge of protocols for seeing adolescents without a guardian. Several clinicians mentioned that that their workflow is interrupted when they are called to approve visits and that poorly trained front desk personnel have at times turned away unaccompanied youth.

Breaches of an adolescent's confidentiality were inadvertent and rare. Breaches were sometimes related to billing (parents receiving an explanation of benefits for an unaccompanied visit), but most common were difficulties getting results to the adolescent without parental knowledge. Almost all clinicians noted a lack of a standardized system for handling confidential results.

\section{DISCUSSION}

Urban primary care clinicians' perspectives provide insights into the process of adolescent primary care, while highlighting strengths and areas needing attention or improvement. Despite competing demands, clinicians seemed committed to providing time alone during preventive care visits. In other types of visits, clinicians described a process of assessing not only the chief complaint, but other variables, including unspoken cues from the teenager and the dynamic between parent and adolescent in deciding whether to include time alone. Depending on these clinical instincts instead of providing routine time alone, however, may result in missed care for adolescents. ${ }^{13}$ Multiple studies indicate that missing needed care remains a serious problem for adolescents. ${ }^{1,11,14-17}$

Although time constraints were noted as the major barrier to offering time alone, clinicians reported little reluctance to ask parents to leave. With occasional memorable exceptions, they perceived that parents were receptive to time alone. Clinicians generally spent little time discussing time alone with parents but had some strategies to help ensure parental comfort: they prepared parents during visits with preteens, used normative language to introduce time alone, offered time alone consistently, and made a conscious effort to avoid making parents feel excluded. The limited research that explores parents' perspectives suggests that clinicians may be underestimating parental discomfort, especially among parents of girls. ${ }^{18,19}$

Importantly, most difficult interactions with parents were related to requests for test results. Parental discomfort was associated with wanting to be fully aware of their children's health problems. Clinicians feel conflicted between the need to protect adolescent confidentiality and the desire to engage the family to support teens; this tension was strongest when adolescents were younger or facing medical decision making. Clinicians dealt with this tension by encouraging parent-teen communication and offering themselves as mediators to facilitate such communication.

Research indicates that many adolescents have limited understanding of their right to confidential services, ${ }^{20,21}$ and that primary care clinicians do not always discuss confidentiality with patients. ${ }^{5,16,22,23}$ Expert guidelines recommend routine discussions of confidentiality protections, including the limitations of confidentiality protections, with both adolescents and their parents. ${ }^{7}$ The self-report data in this study suggest clinicians perceive that they routinely explain confidentiality to youth but are much less likely to include parents in the discussion. Clinicians may skip this step to save time, but they also indicated that they did not want to antagonize parents. Failure to address confidentiality with parents and teens together may contribute to the skepticism of some adolescents that confidentiality protections will be followed.

Insights from this qualitative study were used to derive recommendations for a pilot intervention to improve delivery of sexual health services to adolescents. Specific practice changes included incorporating prompts that serve as a reminder for clinicians to include time alone, as well as such adjuncts as written materials to standardize the process of informing parents and adolescents about the role of confidentiality. We encouraged clinicians to routinely introduce the purpose of time alone, as well as confidentiality protections, with youth and parents together. Our training sessions used cases to explore strategies to handle challenging situations, including the clinician's role as mediator. We recommend that residency curriculum include opportunities to develop skills to facilitate adolescent-parent communication.

A key difference between adolescent and family care settings was noted in this study. In adolescent settings, a clear transition from pediatric care to adolescent care occurs when an individual's care moves to the practice. Clinicians described a routine process of informing parents and adolescents how care is provided and the role of confidentiality. Pediatricians and 
family physicians that see children of all ages lack a clear transition where adolescents' independence from parents is established. A suggestion offered is that clinicians in family care settings develop office systems to facilitate a transition, such as letters or fliers for parents and adolescents that outline how care processes change for teenagers.

Clinicians in almost all practices noted lack of office systems and inconsistent procedures for determining whether unaccompanied youth would be seen. Others have noted that office staff is not trained to give accurate information about available confidential services. ${ }^{11}$ Clinicians also noted unofficial cliniciandependent procedures to convey confidential results to adolescents. Our data suggest the need for training office staff, and more systematic methods to maintain confidentiality while getting results to adolescent patients (eg, routine collection of an e-mail address or cell phone number as a means of contact).

Some limitations of the present study should be noted. The intent of using mixed methods was that the card would serve as a trigger to generate discussion of specific cases. To some extent this happened, but clinicians still tended to tell us what they typically do or say, which likely reflected idealized versions. The cards were still useful in grounding the discussion about including or not including time alone in recent actual encounters. Additionally, clinicians provided informative accounts of difficult situations that mostly did not occur during the study period. These urban hospital-owned practices provide care to a high proportion of patients insured by Medicaid. Results from such practices might not generalize to other settings. Among other differences, payment and billing issues vary substantially between hospital-owned and private practices. Our participants routinely provide confidential services to teens; such is not the case in all of primary care. ${ }^{11,12,24,25}$ Finally, our sample was primarily female, which may bias our results if there are differences by sex in how clinicians interact with adolescents and parents.

Despite limitations, these data contribute to a growing body of evidence documenting the timing and content of confidential care service provision to adolescents from the perspective of clinicians in urban primary care. These clinicians are committed to offering time alone for adolescents during the preventive health visit despite competing time demands, but infrequently offer it at other times. Furthermore, clinicians consider their role as one of facilitating the complex relationship between adolescents and their parents to optimize health outcomes. Finally, our findings indicate that systemic changes are needed to enhance the quality and delivery of confidential services for adolescents.
To read or post commentaries in response to this article, see it online at http://www.annfammed.org/cgi/content/full/9/1/37.

Key words: Adolescents; confidentiality; primary health care; qualitative research

Submitted March 19, 2010; submitted, revised, July 8, 2010; accepted July 12, 2010.

Funding support: McKee received funding from the National Institute of Child Health and Human Development, R21HD054326. Dr Rubin's salary was supported by a fellowship grant from the New York State Empire Clinical Research Investigator Program.

Findings from this study were displayed in a poster presentation at the 37th annual meeting of the North American Primary Care Research Group, November 14-18, 2009, West Montreal, Quebec, Canada.

\section{References}

1. Ford CA, Bearman $P$, Moody J. Foregone health care among adolescents. JAMA. 1999;282(23):2227-2234.

2. Lehrer JA, Pantell R, Tebb K, Shafer MA. Forgone health care among US adolescents: associations between risk characteristics and confidentiality concern. J Adolesc Health. 2007;40(3):218-226.

3. Ford C, Millstein S, Halpern-Felsher B, Irwin CJ. Influence of physician confidentiality assurances on adolescents' willingness to disclose information and seek future health care. A randomized controlled trial. JAMA. 1997;278(12):1029-1034.

4. Reddy DM, Fleming R, Swain C. Effect of mandatory parental notification on adolescent girls' use of sexual health care services. JAMA. 2002;288(6):710-714.

5. Thrall J, McCloskey L, Ettner S, Rothman E, Tighe J, Emans S. Confidentiality and adolescents' use of providers for health information and for pelvic examinations. Arch Pediatr Adolesc Med. 2000;154(9):885-892.

6. Morreale MC, Stinnett AJ, Dowling EC. Policy Compendium on Confidential Health Services for Adolescents. 2nd ed. Chapel Hill, NC: Center for Adolescent Health \& the Law; 2004.

7. Ford CA, English A, Sigman G. Confidential health care for adolescents: Position paper of the society for adolescent medicine. J Adolesc Health. 2004;35(2):160-167.

8. Klein J, Wilson K, McNulty M, Kapphahn C, Collins K. Access to medical care for adolescents: results from the 1997 Commonwealth Fund Survey of the Health of Adolescent Girls. J Adolesc Health. 1999;25(2):120-130.

9. Edman JC, Adams SH, Park MJ, Irwin CE. Who gets confidential care? Disparities in a national sample of adolescents. J Adolesc Health. 2010;46(4):393-395.

10. Ford CA. Which adolescents have opportunities to talk to doctors alone? J Adolesc Health. 2010;46(4):307-308.

11. Akinbami LJ, Gandhi H, Cheng TL. Availability of adolescent health services and confidentiality in primary care practices. Pediatrics. 2003;111(2):394-401

12. O'Sullivan L, McKee MD, Rubin SE, Campos G. Primary care providers' reports of time alone and the provision of sexual health services to adolescent patients: results of a prospective card study. J Adolesc Health.2010;47(1):110-112.

13. Oscos-Sanchez MA, White D, Bajorek E, et al. SAFE TEENS: Facilitators of and barriers to adolescent preventive care discussions. Fam Med. 2008;40(2):125-131. 
14. Rew L, Resnick M, Beuhring T. Usual sources, patterns of utilization, and foregone health care among Hispanic adolescents. J Adolesc Health. 1999;25(6):407-413.

15. McKee MD, Fletcher J, Schechter CB. Predictors of timely initiation of gynecologic care among urban adolescent girls. J Adolesc Health. 2006;39(2):183-191.

16. Fairbrother G, Scheinmann R, Osthimer B, et al. Factors that influence adolescent reports of counseling by physicians on risky behavior. J Adolesc Health. 2005;37(6):467-476.

17. Brown JD, Wissow LS. Discussion of sensitive health topics with youth during primary care visits: relationship to youth perceptions of care. J Adolesc Health. 2009;44(1):48-54.

18. Ford CA, Davenport AF, Meier A, McRee A-L. Parents and health care professionals working together to improve adolescent health: the perspectives of parents. J Adolesc Health. 2009;44(2):191-194.

19. McKee M, O'Sullivan L, Weber C. Perspectives on confidential care for adolescent girls. Ann Fam Med. 2006;4(6):519-526.

20. Ford C, Thomsen S, Compton B. Adolescents' interpretations of conditional confidentiality assurances. J Adolesc Health. 2001; 29(3):156-159.
21. Cheng T, Savageau J, Sattler A, DeWitt T. Confidentiality in health care. A survey of knowledge, perceptions, and attitudes among high school students. JAMA. 1993;269(11):1404-1407.

22. Halpern-Felsher B, Ozer E, Millstein S, et al. Preventive services in a health maintenance organization: how well do pediatricians screen and educate adolescent patients? Arch Pediatr Adolesc Med. 2000;154(2):173-179.

23. Rutishauser C, Esslinger A, Bond L, Sennhauser FH. Consultations with adolescents: the gap between their expectations and their experiences. Acta Paediatr. 2003;92(11):1322-1326

24. Blum R, Beuhring T, Wunderlich M, Resnick M. Don't ask, they won't tell: the quality of adolescent health screening in five practice settings. Am J Public Health. 1996;86(12):1767-1772.

25. Kelts $E$, Allan M, Klein J. Where are we on teen sex?: Delivery of reproductive health services to adolescents by family physicians. Fam Med. 2001;33(5):376-381.

Please complete this form and mail to the following address or fax to Annals Circulation at 913-906-6080:

Annals of Family Medicine, Circulation Department, 11400 Tomahawk Creek Pkwy, Leawood, KS 66211-2680

Check if member of sponsoring organization: $\square$ AAFP $\square$ ABFM $\square$ STFM $\square$ ADFM

$\square$ AFMRD $\square$ NAPCRG $\square$ CFPC

ID number from label on your journal cover

OLD Information (Please print.)

\section{Name}

Company (if applicable)

Address (Street plus Apt or Ste)

City

Country

Telephone

E-Mai
NEW Information (Please print.)

\begin{tabular}{ll}
\hline Name \\
\hline Company (if applicable) \\
\hline Address (Street plus Apt or Ste) & \\
\hline City & Postal Code (9-digit ZIP for US) \\
\hline Country & Fax \\
\hline Telephone & \\
\hline E-Mail &
\end{tabular}

